OAUTOR

\title{
Eduardo Meditsch
}

Professor Doutor na Universidade Federal de Santa Catarina e coordenador do Grupo de Estudos sobre Jornalismo da Associação Latino-Americana de Pesquisadores da Comunicação - Alaic.

E-mail: emeditsch@uol.com.br

\section{FILOSOFIA DE PAULO FREIRE E PRÁTICAS COGNITIVAS NO JORNALISMO ${ }^{1}$}

Jornalismo propõe método de conhecimento da realidade diversa do método científico

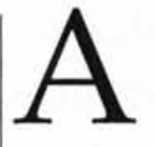

atividade jornalística, desde a escola, tem se caracterizado por uma violenta dicotomia entre o saber sobre e o saber fazer. A pesquisa teórica e a produção crítica passam ao largo dos problemas da prática, como se esta fosse uma dimensão estranha ao pensamento, e respondem a perguntas formuladas em contextos alheios. O saber fazer, no mais das vezes, despreza esta teoria e se reproduz com base na experiência acumulada e nas influências culturais, políticas, econômicas e tecnológicas que atuam sobre ela. Este descompasso, no entanto, se é típico das áreas de jornalismo e da comunicação social, não é uma exclusividade delas. E foi por diagnosticá-lo e pretender enfrentá-lo na sua área de atuação, a Pedagogia, que Paulo Freire desenvolveu o seu método de ensino-aprendizagem e toda a sua concepção filosófica da educação.

Dessa forma, uma aplicação adequada das idéias de Freire ao campo jornalístico não deve produzir apenas uma ferramenta teórica que ajude a compreendê-lo do ponto de vista meramente descritivo. A compreensão da realidade, para Freire, é apenas um momento do ciclo maior que leva à sua permanente transformação pelo ser humano que a compreende: “...esse movimento do mundo à palavra e da palavra ao mundo está sempre presente. Movimento em que a palavra dita flui do mundo mesmo através da leitura que dele fazemos. De alguma maneira, porém, po-

1. Comunicação originalmente apresentada no VI Congresso da Brazilian Studies Association (BRASA VI) Atlanta (USA), 4 a 6 de abril de 2002, dentro do painel: The Past and the Future of Journalism: Representation, Pedagogy and Digital Communication, sob a coordenação de Raul Reis. 
demos ir mais longe e dizer que a leitura da palavra não é apenas precedida pela leitura do mundo mas por uma certa forma de escrevê-lo, ou de reescrevê-lo, quer dizer, de transformá-lo através de nossa prática consciente" 2 .

Somente o compromisso do pensamento com a prática estabelece para Freire um "contexto teórico verdadeiro". "Não há contexto teórico verdadeiro a não ser em unidade dialética com o contexto concreto. Nesse contexto, onde os fatos se dão, nos encontramos envolvidos pelo real, molhados nele, mas não necessariamente percebendo a razão de ser dos mesmos fatos, de forma crítica. No contexto teórico, tomando distância do concreto, buscamos a razão de ser dos fatos. Em outras palavras, procuramos superar a mera opinião que deles temos e que a tomada de consciência dos mesmos nos proporciona, por um conhecimento cabal, cada vez mais científico em torno deles. No contexto concreto somos sujeitos e objetos em relação dialética com o objeto; no contexto teórico assumimos o papel de sujeitos cognoscentes da relação sujeito-objeto que se dá no contexto concreto para, voltando a este, melhor atuar como sujeitos em relação ao objeto. (...) Daí a necessidade que temos, de um lado, de ir mais além da mera captação da presença dos fatos, buscando, assim, não só a interdependência que há entre eles, mas também o que há entre as parcialidades constitutivas da totalidade de cada um e, de outro lado, a necessidade de estabelecermos uma vigilância constante sobre nossa própria atividade pensante" ${ }^{\text {"3 }}$.
Ao longo de sua vida intelectual, Freire se tornará cada mais enfático em relação à necessidade desta vigilância do pensamento: "...pensar sempre a prática. De fato, pensar a prática de hoje não é apenas um caminho eficiente para melhorar a prática de amanhã, mas também a forma eficaz de aprender a pensar certo" 4 . Para o educador, a Universidade não estaria mais ensinando a "pensar certo" neste sentido: "...tal qual um estudante universitário, com seu treinamento abstrato em linguagem abstrata, em que a ênfase se faz na descrição dos conceitos que devem mediar a compreensão do concreto. Em lugar de você usar o conceito para mediar, como mediador da compreensão do concreto, você termina ficando na descrição do conceito. Este é o comportamento do nosso jovem dentro da universidade" .

Para Paulo Freire, o trabalho teórico desenvolvido à margem de qualquer prática tenderia a se transformar em mero jogo.

"Nossa experiência na universidade tende a nos formar a distância da realidade. Os conceitos que estudamos na universidade podem trabalhar no sentido de nos separar da realidade concreta à qual, supostamente, se referem. Os próprios conceitos que usamos em nossa formação intelectual e em nosso trabalho estão fora da realidade, muito distantes da sociedade concreta. Em última análise, tornamonos excelentes especialistas, num jogo

2. FREIRE, P. A importância do ato de ler. São Paulo: Cortez, 1982. p. 22.

3. FREIRE, P. Ação cultural para a liberdade e outros escritos. Rio de Janeiro: Paz e Terra, 1976. p. $135-136$.

4. FREIRE, P. FREI BETTO. Essa escola chamada vida. São Paulo: Ática, 1986. p. 9.

5. FREIRE, P; FREI BETTO. Essa escola ... op. cit. p. 10. 
intelectual muito interessante-o jogo dos conceitos: é um balé de conceitos"

Por fim, Freire adverte que esta redução da atividade intelectual a um jogo acaba por desvalorizá-la, inibindo a sua força transformadora: "quanto mais essa dicotomia entre ler palavras e ler realidade se exerce na escola, mais nos convencemos de que nossa tarefa, na escola ou na faculdade, é apenas trabalhar com conceitos, apenas trabalhar com textos que falam de conceitos. Porém, na medida em que estamos sendo treinados numa vigorosa dicotomia entre o mundo das palavras e o mundo real, trabalhar com conceitos escritos num texto significa obrigatoriamente dicotomizar o texto do contexto.

\section{E então nos tornamos, cada vez mais, especialistas em ler palavras, sem nos preocupar em vincular a leitura com uma melhor compreensão do mundo.}

Em última análise, distinguimos o contexto teórico do contexto concreto. Uma pedagogia dicotomizada como esta diminui o poder do estudo intelectual de ajudar na transformação da realidade" 7 .

Para Berthoff, a prática de Freire é inteiramente pragmática. "Paulo Freire é um dos verdadeiros herdeiros de William James e de Charles Sanders Pierce. Ele nos diz: o modo como funciona a sua teoria e o que ela faz mudar lhe dirá melhor o que é a sua teoria. Ele quer que consideremos o valor de uma idéia, perguntando o que ela importa" ${ }^{1}$. Embora reconheça a importância desta influência em sua formação, Freire distinguirá entre um pragmatismo que aprendeu da Escola Nova de John Dewey, e que considera progressista, de um outro "pragmatismo" posto entre aspas, típico do neoliberalismo, que conduz ao fatalismo e à acomodação, com o qual não se identifica? .

É que além do pragmatismo norte-americano, Freire sofrerá influência da concepção de práxis que encontra na leitura de Gramsci, de Marx e de seus intérpretes, e que vai ajudar a fundamentar mais tarde a sua proposta pedagógica, explicada ela mesmo como "teoria de conhecimento posta em prática". Teoria do conhecimento que Freire irá buscar em filósofos como Karel Kosik, Adolfo SánchezVásquez e Álvaro Vieira Pinto, assim como em obras do próprio Marx.

Em vários momentos, Freire se refere às Teses sobre Feuerbach ${ }^{10}$, destacando o fato de o pensador alemão haver escrito, em apenas uma página e meia, "uma das mais importantes obras da filosofia ocidental". Como destaca Sánchez-Vázquez, "Marx formula em suas Teses sobre Feuerbach uma concepção de objetividade, fundamentada na práxis, e define a sua filosofia como a filosofia de transformação do mundo. (...) Isto é, ao colocar no

6. FREIRE, Paulo; SHOR, Ira. Medo e ousadia: o cotidiano do professor. Rio de Janeiro: Paz e Terra, 1987. p. 131. 7. FREIRE, Paulo; SHOR, Ira. Medo e ousadia... op. cit. p. 165.

8. BERTHOFF, Ann E. Prefácio In: FREIRE, Paulo; MACEDO, Donaldo. Alfabetização: leitura do mundo, leitura da palavra. Rio de Janeiro: Paz e Terra, 1987. p. xv-xxvii.

9. FREIRE, P. Pedagogia da indignação. São Paulo: Editora Unesp, 2000. p. 123-124.

10. MARX, Karl. Teses sobre Feuerbach. In: MARX, K. ENGELS, F. Obras escolhidas. v. 3. São Paulo: Alfa Ômega, [s.d.]. p. 208-210. (N. Ed.) 
centro de toda relação humana a atividade prática, transformadora do mundo, isso não pode deixar de ter consequiências profundas no terreno do conhecimento. A práxis aparecerá como fundamento (Tese I), critério de verdade (Tese III) e finalidade do conhecimento" ". Desta forma, o primado da prática em Freire significará um compromisso da teoria com a transformação da realidade. E nessa perspectiva é que ele abordaria a questão da prática jornalística.

\section{JORNALISMO E CONHECIMENTO}

Em 1987, durante a elaboração de minha dissertação de mestrado na USP, tive a oportunidade de acompanhar uma disciplina ministrada por Paulo Freire, então professor-visitante da Escola de Comunicações e Artes, e de ser recebido em sua casa para discutir minha pesquisa sobre o jornalismo como forma de produção de conhecimento e o seu ensino ${ }^{12}$.

$\mathrm{Na}$ ocasião, expus rapidamente ao pedagogo a tese do jornalismo enquanto forma de conhecimento sustentada por meu colega Adelmo Genro Filho ${ }^{13}$, e comparei a atividade jornalística com a educativa, enquanto "uma teoria do conhecimento posta em prática", como Paulo Freire propunha, ainda que em uma prática diferenciada. Freire considerou a analogia válida e me entusiasmou a avançar no projeto. Embora evitasse tratar teoricamente a questão da mídia em sua obra, por não se considerar um especialista competente no assunto, ela o interessava dentro do horizonte geral da teoria do conhecimento que desenvolvia em seus trabalhos sobre educação, como testemunhou a Sérgio Guimarães ${ }^{14} \mathrm{em}$ um de seus livros dialogados.

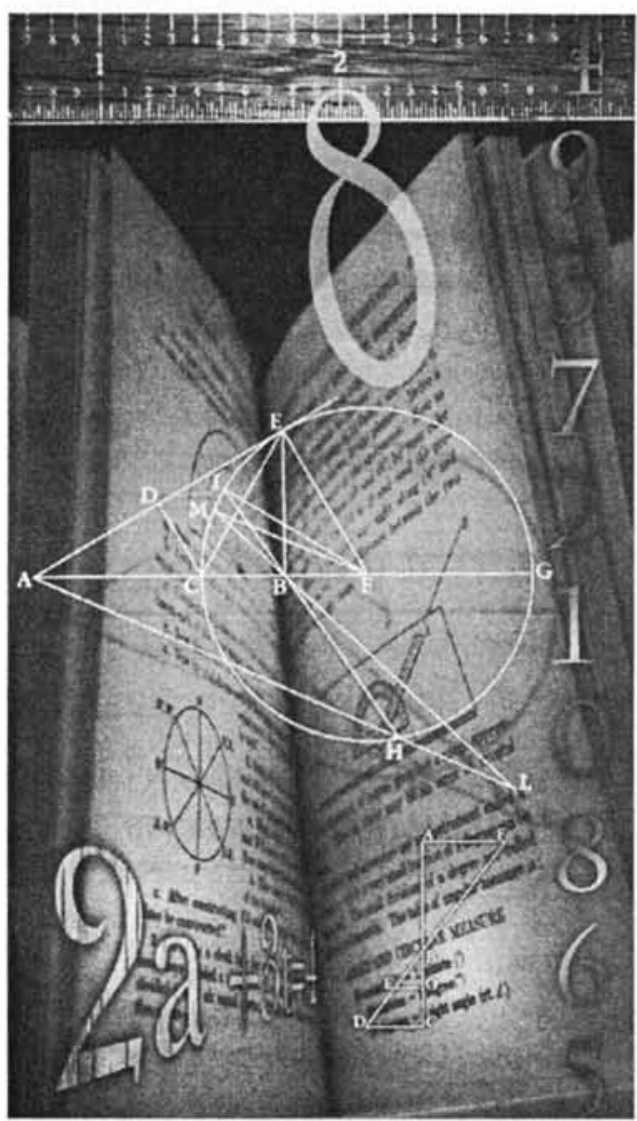

American Showcase

A questão do Jornalismo enquanto conhecimento, que levei a ele, era produto do acúmulo de uma discussão antiga, envolvendo diversas interpretações. Para simplificar a exposição, vou

11. SÁNCHEZ-VÁZQUEZ, Adolfo. Filosofia da práxis. Rio de Janciro: Paz e Terra, 1986. p. 149.

12. MEDITSCH, E. O conhecimento do jornalismo. Florianópolis: Editora da Universidade Federal de Santa Catarina, 1992.

13. GENRO FILHO, Adelmo. O segredo da pirâmide: para uma teoria marxista do jornalismo. Porto Alegre: Tchê, 1987.

14. FREIRE, P., GUIMARĀES, S. Sobre educação. Diálogos. v.2. Rio de Janeiro: Paz e Terra, 1984. p. 40. 
aqui classificar estas interpretações, que compreendem diferentes nuanças, em três abordagens principais.

A primeira delas nasce da definição de conhecimento não como um dado concreto, mas como um ideal abstrato a alcançar. Uma vez estabelecido, esse ideal passa a ser o parâmetro para julgar toda espécie de conhecimento produzido no mundo humano. A era moderna, com as fantásticas realizações da técnica na transformação da vida humana e no domínio da natureza, acabou por realizar o sonho dos filósofos positivistas de entronizar a Ciência como única fonte de conhecimento digna de crédito. $\mathrm{O}$ método científico foi escolhido como o parâmetro adequado para se conhecer e dominar o mundo, e toda a tentativa de conhecimento estabelecida à margem deste padrão foi desmoralizada, considerada imperfeita e pouco legítima.

Esta visão que entroniza a Ciência como o método de conhecimento estabelece a primeira das abordagens do problema do Jornalismo em relação ao conhecimento: para ela, o Jornalismo não produz conhecimento válido e contribui apenas para a degradação do saber. São notáveis as observações do intelectual austríaco Karl Kraus a este respeito, escritas no início do século: "O que a sífilis poupou será devastado pela imprensa. Com o amolecimento cerebral do futuro, a causa não poderá mais ser determinada com segurança.(...) A imagem de que um jornalista escreve tão bem sobre uma nova ópera como sobre um novo regulamento parlamentar tem algo de acabrunhante. Seguramente, ele também poderia ensinar um bacteriologista, um astrônomo e até mesmo um padre. E se viesse a encontrar um especialista em matemática superior, the provaria que se sente em casa numa matemática ainda mais superior"15.

Kraus não representa um crítico isolado. Seu pensamento influenciou profundamente muitos outros intelectuais de respeito, como Walter Benjamin e os fundadores da Escola de Frankfurt. Apesar das críticas que este ponto de vista vem recebendo nos últimos anos, sua influência ainda pode ser constatada em grande parte da produção acadêmica contemporânea sobre o Jornalismo, que de uma forma ou de outra o situa no campo do conhecimento como uma ciência mal feita, quando não como uma atividade perversa e degradante.

Obviamente, não seria essa a posição de Freire sobre o jornalismo, embora tivesse uma posição bastante crítica sobre o seu exercício, especialmente na realidade brasileira, na época em que conversamos. Na ocasião, ele falou um pouco de sua percepção do trabalho dos profissionais da grande imprensa, como se dizia.

Na sua opinião, o objetivo comercial dominante estava impossibilitando um trabalho mais sério por parte dos jornalistas brasileiros, especialmente do telejornalismo.

Ele próprio se sentia usado quando era chamado para alguma entrevista, segun-

15. KRAUS, Karl. Sprueche und Widersprueche, 1918. Trad. Bras. Ditos e Contraditos. In: Karl Kraus (1874-1936) ou o ódio ao jornalismo. Folha de S. Paulo, 5/8/1984. 
do ele mais para rechear um produto comercial do que para efetivamente ser levado em consideração no que tinha a dizer.

É de se considerar que Freire havia retornado do exílio há poucos anos, período em que conviveu mais de perto com a imprensa européia, que tradicionalmente tem maior respeito pelo trabalho intelectual e pela pluralidade de idéias, para não dizer pelo seu público. No diálogo com Sérgio Guimarães, havia registrado que, em sua opinião, o público europeu, francês ou suíço não toleraria a apelação da TV comercial brasileira ou norte-americana, embora vivesse em sociedades igualmente capitalistas ${ }^{16}$. Esta observação o levava a crer, otimistamente, que um pequeno progresso em nossas sociedades poderia provocar melhoras significativas na forma de utilizar a mídia que, em sua opinião, havia superado a escola enquanto instituição em vários aspectos e por isso deveria ser aproveitada em qualquer projeto educativo.

\section{ABORDAGENS QUANTITATIVA E QUALITATIVA}

Uma segunda forma de abordagem do Jornalismo enquanto conhecimento o situa ainda como uma ciência menor, mas admite já que não é de todo inútil. Pode-se localizar a origem desta abordagem no trabalho doex-jornalista e sociólogo do conhecimento Robert Park, que publicou um artigo sobre o tema em $1940^{17}$. A partir da perspectiva filosófica do pragmatismo de William James, que abandona o conhecimento como um ideal para observá-lo como um dado da vida humana, concluindo que as pessoas e as coletividades lidam simultaneamente em suas vidas com várias espécies de conhecimento, Park começa a definir o Jornalismo a partir do que tem de diferente, do que lhe é específico como forma de conhecimento da realidade.

Embora admita a distinção entre tipos de conhecimento, o sociólogo norte-americano não avança neste aspecto muito além do que James já havia realizado ao distinguir entre um conhecimento de utilizado no cotidiano e um conhecimento sobre, sistemático e analítico, como o produzido pelas ciências. Para situar o Jornalismo, Park vai propor a existência de uma gradação entre as duas espécies de conhecimento e colocar a notícia num nível intermediário entre elas.

Este tipo de diferenciação do Jornalismo a partir do grau de profundidade que alcança comparativamente a Ciência ou a História é admitida pelos próprios jornalistas. Ao fazerem comparações entre o seu trabalho e o dos cientistas, os jornalistas costumam sugerir esta forma de gradação.

\section{Quando não se refere à} profundidade de análise, a gradação pode referir-se também à velocidade da produção, e o Jornalismo já foi definido como a História escrita à queima-roupa.

$\mathrm{O}$ enquadramento da forma de conhecimento do jornalismo estabelecido por

16. FREIRE, P. GUIMARÃES, S. Sobre educação... op. cit. p. 35.

17. PARK, Robert E. A notícia como forma de conhecimento; um capítulo da sociologia do conhecimento. (1940). In: STEINBERG, Charles. Meios de comunicação de massa. São Paulo: Cultrix, 1972. 
Park, num grau intermediário entre o senso comum e a ciência, encontra apoio na distinção entre estas formas de conhecer, a qual é realçada ao longo da obra de Freire. Num de seus últimos livros, o pedagogo reafirma: "Não há para mim, na diferença e na distância entre a ingenuidade e a criticidade, entre o saber de pura experiência feito e o que resulta dos procedimentos metodicamente rigorosos, uma ruptura, mas uma superação. A superação e não a ruptura se dá na medida em que a curiosidade ingênua, sem deixar de ser curiosidade, pelo contrário, continuando a ser curiosidade, se criticiza. Ao criticizar-se, tornando-se, então, permitome repetir, curiosidade epistemológica, metodicamente 'rigorizando-se' na sua aproximação ao objeto, conota seus achados de maior exatidão. Na verdade, a curiosidade ingênua que, 'desarmada', está associada ao saber do senso comum, é a mesma curiosidade que, criticizando-se, aproximando-se de forma cada vez [mais] metodicamente rigorosa do objeto cognoscível, se torna curiosidade epistemológica. Muda de qualidade mas não de essência"18.

No entanto, como propõe Freire, entre os vários graus de conhecimento observados por Park ocorre também uma mudança de qualidade e, neste sentido, a comparação quantitativa dos atributos do Jornalismo em relação à Ciência ou à História, estabelecida pelo sociólogo norteamericano, pode ser útil para elucidar algumas das suas diferenças, mas parece insuficiente para definir o que ele tem de específico. Daí que tenha surgido uma terceira abordagem, que dá mais ênfase não ao que o Jornalismo tem de semelhante, mas justamente ao que ele tem de único e original. Para esta terceira abordagem, que tem sido desenvolvida por teóricos brasileiros, especialmente na Universidade Federal de Santa Catarina, o Jornalismo não revela mal nem revela menos a realidade do que a Ciência: ele simplesmente revela diferente. $\mathrm{E}$ ao revelar diferente, pode mesmo revelar aspectos da realidade que os outros modos de conhecimento não são capazes de revelar.

Conforme Freire, "uma das condições para que um fato, um fenômeno, um problema seja entendido em sua rede de relações, é que se torne, dialeticamente, um destacado percebido em si. Primeiro que o compreendamos como algo nele mesmo para assim perceber que sua compreensão envolve suas relações com outros dados ou fatos" ${ }^{\prime 19}$. É esta força na revelação dos fatos que caracteriza o jornalismo e o distingue da prática teórica exercida na academia e sempre criticada por Freire, como em seu diálogo com o educador norte-americano Ira Shor: "Nossa experiência na universidade tende a nos formar à distância da realidade. Os conceitos que estudamos na universidade podem trabaIhar no sentido de nos separar da realidade concreta à qual, supostamente, se referem. Os próprios conceitos que usamos em nossa formação intelectual e em nosso trabalho estão fora da realidade, muito distantes da sociedade concreta. (...) Assim, nossa linguagem corre o risco de perder o contato com o concreto. Quanto mais somos assim, mais distantes estamos da massa das pessoas, cuja linguagem, pelo contrário, é absolutamente ligada ao

18. FREIRE, P. Pedagogia da autonomia. São Paulo: Paz e Terra, 1996. p. 34.

19. FREIRE, P. Cartas a Cristina. Rio de Janeiro: Paz e Terra, 1994. p. 226. 
concreto. (...) Não dicotomizo essas duas dimensões do mundo - vida diária do rigor, senso comum do senso filosófico, na expressão de Gramsci. Não compreendo conhecimento crítico ou científico que aparece por acaso, por um passe de mágica ou acidente, como se não precisasse se submeter ao teste da realidade. $\mathrm{O}$ rigor científico vem de um esforço para superar uma visão ingênua do mundo. A ciência sobrepõe o pensamento crítico àquilo que observamos na realidade, a partir do senso comum" 20 .

Além de uma maneira distinta de produzir conhecimento, o jornalismo também tem uma maneira diferenciada de o reproduzir, vinculada à função de comunicação que lhe é inerente. O Jornalismo não apenas reproduz o conhecimento que ele próprio produz, reproduz também o conhecimento produzido por outras instituições sociais. A hipótese de que ocorra uma re-produção do conhecimento, mais complexa do que a sua simples transmissão, ajuda a entender melhor o papel do Jornalismo no processo de cognição social. Esta hipótese é corroborada por Freire em seu trabalho sobre a educação: "....a curiosidade diante do objeto a ser desvelado, esse não estar conformado com o que se tem e com o que se sabe; esse sair de dentro da gente mesmo, essa procura impacientemente paciente, portanto metódica, bem comportada mas não acomodada; essa posição de quem vai realmente tirando o véu das coisas, é absolutamente indispensável ao sujeito que conhece e ao sujeito que quer conhecer, ou que conhece o que já se conhece e que quer criar o que ainda não se conhece. Essa curiosidade é o opos- to da posição dócil, apassivada, de puro recipiente de um pacote que se transfere ao sujeito dócil. Daí a crítica que fiz, anos atrás, na Pedagogia do Oprimido, ao que chamei de educação bancária.... a crítica que fiz à posição do professor ou do educador como transferidores de conhecimento, que para mim é um absurdo. $\mathrm{O}$ conhecimento não se transfere: se sabe, se conhece, se cria, se recria, curiosamente, arriscadamente" 21 .

Ao utilizar a distinção entre conhecimento de e conhecimento sobre, o primeiro sintético e intuitivo, o segundo sistemático e analítico, dentro da tradição do pragmatismo, Robert Park observa que o Jornalismo realiza para o público as mesmas funções que a percepção realiza para os indivíduos.

\section{A partir de Freire, poder-se-ia dizer que o jornalismo opera a tomada de consciência, que se distingue da conscientização.}

"A tomada de consciência se verifica na posição espontânea que meu corpo consciente assume em face do mundo, da concretude dos objetos singulares. A tomada de consciência é, em última análise, a presentificação à minha consciência dos objetos que capto no mundo em que e com que me encontro. Por outro lado, os objetos se acham presentificados à minha consciência e não dentro dela.(...) A tomada de consciência é o ponto de partida. É tomando consciência do objeto que eu primeiro me dou conta dele. Dando-se à 
minha curiosidade, o objeto é conhecido por mim"22.

Conforme Lage, "o Jornalismo descende da mais antiga e singela forma de conhecimento - só que, agora, projetada em escala industrial, organizada em sistema, utilizando fantástico aparato tecnológico" ${ }^{23}$. Genro Filho ${ }^{24}$ também ressalva que o Jornalismo como gênero de conhecimento difere da percepção individual pela sua forma de produção: nele, a imediaticidade do real é um ponto de chegada, e não de partida. Esta ressalva é importante para se discutir os problemas do Jornalismo como forma de conhecimento e de seus efeitos. No entanto, ao se fixar na imediaticidade do real, o Jornalismo opera no campo lógico do senso comum, e esta característica definidora é fundamental.

\section{COTIDIANO COMO OBJETO DO CONHECIMENTO}

A partir dela, pode-se questionar até que ponto o Jornalismo como modo de conhecimento pode ser rigoroso. $\mathrm{O}$ conhecimento do senso comum foi, até bem pouco tempo, desprezado pela teoria, uma vez que toda a ciência moderna se constituiu com base na sua negação. Mas, na medida em que as Ciências Humanas passaram a valorizar a observaçãodo cotidiano para odesvendamento das relações sociais, o que era visto como irrelevante, ilusório e falso começou a aparecer não só como um objeto digno de consideração pela teoria do conhecimento mas, em última análise, como o seu objeto principal ${ }^{25}$.
Conforme Berger e Luckmann, o senso comum corresponde a uma atitude cognitiva percebida como natural. "A atitude natural é a atitude da consciência do senso comum precisamente porque se refere a um mundo que é comum a muitos homens. O conhecimento do senso comum é o conhecimento que eu partilho com os outros nas rotinas normais, evidentes da vida cotidiana" ${ }^{26}$. Além disso, a atitude cognitiva natural estabelece uma certa percepção da realidade como dominante. "Comparadas à realidade da vida cotidiana, as outras realidades aparecem como campos finitos de significação, enclaves dentro da realidade dominante, marcadas por significados e modos de experiência delimitados. A realidade dominante envolve-as por todos os lados, por assim dizer, e a consciência sempre retorna à realidade dominante como se voltasse de uma excursão". "Todos os campos finitos de significação caracterizam-se por desviar a atenção da realidade da vida cotidiana. (...) É importante, porém, acentuar que a realidade da vida cotidiana conserva a sua situação dominante mesmo quando estes 'transes' ocorrem. Se nada mais houvesse, a linguagem seria suficiente para nos assegurar sobre este ponto. A linguagem comum de que disponho para a objetivação de minhas experiências funda-se na vida cotidiana e conserva-se sempre apontando para ela mesma quando a emprego para interpretar experiências em campos delimitados de significação"27.

22. FREIRE, P. Cartas a... op. cit. p. 224-225.

23. LAGE, N. Prefácio. In: MEDITSCH, E. O conhecimento ... op. cit. p. 14-15.

24. GENRO FILHO, Adelmo. O segredo da pirâmide... op. cit. p. 58.

25. SANTOS, Boaventura de Souza. Um discurso sobre as ciências. Porto: Afrontamento, 1988.

26. BERGER, Peter, LUCKMANN, Thomas. A construção social da realidade. Petrópolis: Vozes, 1973. p. 40.

27. BERGER, Peter, LUCKMANN, Thomas. A construção... op. cit. p. 43-44. 
É o fato de operar no campo lógico da realidade dominante que assegura ao modo de conhecimento do Jornalismo tanto a sua fragilidade quanto a sua força enquanto argumentação.

É frágil, enquanto método analítico $\mathrm{e}$ demonstrativo, uma vez que não pode se descolar de noções pré-teóricas para representar a realidade. É forte na medida em que essas mesmas noções pré-teóricas orientam o princípio de realidade de seu público, nele incluídos cientistas e filósofos quando retornam à vida cotidiana, vindos de seus campos finitos de significação. Em conseqüência, o conhecimento do jornalismo será forçosamente menos rigoroso do que o de qualquer ciência formal mas, em compensação, será também menos artificial e esotérico.

Evidentemente, como todo conhecimento, o senso comum não é tão democrático como sugere o termo. $\mathrm{O}$ conhecimento é repartido socialmente, devido ao simples fato de o indivíduo não conhecer tudo o que é conhecido por seus semeIhantes, e vice-versa, processo que culmina em sistemas de perícia extraordinariamente complexos. A distribuição social de conhecimentos, desta forma, não se dá apenas em termos quantitativos (uns conhecem mais do que outros), mas também qualitativos (conhecem coisas diferentes). Cada campo de conhecimento é compartilhado por um auditório específico. A questão dos auditórios, assim como a dos campos lógicos, estabelece diferenças entre o modo de conhecimento das Ciências e do Jornalismo.

\section{IDEAL DE UNIVERSALIDADE}

A linguagem formal dos cientistas justifica-se por sua universalidade, a universalidade ideal de seu auditório. Porém, esta universalidade será igualmente formal, uma universalidade de direito mas não de fato, uma vez que esta linguagem só circula por determinadas redes e cria uma incomunicação crescente entre os dialetos das diversas especialidades. Neste sentido, quanto mais as Ciências produzem conhecimento, mais tornam opaco este conhecimento ${ }^{28}$. Para penetrar nesta opacidade, é necessário também penetrar na rede institucional que a mantém, através dos processos pedagógicos específicos.

Já o ideal de universalidade do Jornalismo caminha em outra direção. $\mathrm{O}$ auditório universal que idealmente persegue refere-se a uma outra rede de circulação de conhecimento, constituída pela comunicação para devolver à realidade a sua transparência coletiva. É uma universalidade de fato, embora precária, porque só estabelecida institucionalmente de forma indireta e imperfeita, tal e qual o espaço público pressuposto pelo ideal democrático que a precede e a requer. Sua amplitude é também limitada em outra direção, a intenção do emissor na delimitação do universo do público-alvo. Mas é na preservação deste auditório ideal que o Jornalismo encontra uma de suas principais justificações sociais: a de manter a

28. VIEIRA PINTO, Álvaro. Ciência e existência. Rio de Janeiro: Paz e Terra, 1969. p. 165-166. 
comunicabilidade entre o físico, o advogado, o operário e o filósofo.

\section{Enquanto a ciência evolui} reescrevendo o conhecimento do senso comum em linguagens formais e esotéricas, o Jornalismo trabalha em sentido oposto.

Daí Freire destacar a importância de uma imprensa livre mesmo para quem dela não se utiliza ou não se dá conta: "Uma coisa, por exemplo, é a significação que pode ter a liberdade de imprensa para as populações famintas, miseráveis, de nosso país, e outra o que ela representa para as classes populares que já comem, vestem, e dormem mais ou menos. O trágico é que a liberdade de imprensa é absolutamente fundamental quer para os que comem, quer para os que não comem. (...) Muito dificilmente uma população faminta e iletrada, mesmo que às vezes tocada pelo rádio, pode alcançar, antes de comer, o valor para si mesma de uma imprensa livre. Uma vez exercido o direito básico de comer, a negação do exercício de outros direitos vai sendo sublinhada" 29 .

Partindo de premissas retiradas necessariamente do senso comum, a argumentação da notícia parte do que o auditório já sabia, ou era suposto saber. "Se o avião caiu, é claro que existia o avião e que o avião pertence à categoria das coisas capazes de cair" ${ }^{30}$. Em virtude disto, a novidade contida numa notícia é limitada. Como propõe Van Dijk, esta novidade "é a ponta de um iceberg de pressuposições e, em consequiência, da informação previamente adquirida" ${ }^{31}$. Tal constatação sugere que o conhecimento proporcionado pelo Jornalismo tem um duplo papel na construção do senso comum, em que a revelação da novidade refere-se a apenas um aspecto. A compreensão da notícia envolve o processamento "de grandes quantidades de informação estruturadora, repetida e coerente, que sirva como base para ampliações mínimas e outras mudanças em nossos modelos do mundo" 32 . O Jornalismo serve ao mesmo tempo para conhecer e re-conhecer.

\section{A revelação da novidade é um dado estrutural da retórica do} Jornalismo - a conclusão a que
conduz a sua argumentação.

A forma com que chega a esta novidade também é diferente daquela utilizada pela Ciência. Enquanto a Ciência, abstraindo um aspecto de diferentes fatos, procura estabelecer as leis que regem as relações entre eles, o Jornalismo, como modo de conhecimento, tem a sua força na revelação do fato mesmo, em sua singularidade, incluindo os aspectos forçosamente desprezados pelo modo de conhecimento das diversas Ciências.

29. FREIRE, P. Cartas a... op. cit. p. 191.

30. LAGE, N. Ideologia e técnica da notícia. Petrópolis: Vozes, 1979. p. 41.

31. VAN DIJK, T. La noticia como discurso. Compreensión, estructura y producción de la información. (A notícia como discurso: compreensão, estrutura e produção da informação.) Barcelona: Paidós, 1980. p. 176.

32. VAN DIJK, T. La noticia como discurso... op. cit. p. 248. 
Como propusemos em trabalho anterior, no método científico a hipótese pressupõe uma experimentação controlada, isto é, um corte abstrato na realidade através do isolamento de variáveis que permita a obtenção de respostas a um questionamento baseado em sistema teórico anterior. O Jornalismo, por sua vez, não parte de uma hipótese nem de sistema teórico anterior, mas da observação não controlada (do ponto de vista da metodologia científica) da realidade por parte de quem o produz. Também se diferencia das $\mathrm{Ci}$ ências pelo tipo de corte abstrato que propõe. $\mathrm{O}$ isolamento de variáveis é substituído pelo ideal de apreender o fato de todos os pontos de vista relevantes, ou seja, em sua especificidade ${ }^{33}$.

Genro Filho apóia-se nas categorias hegelianas do universal, particular e singular para definir o modo de conhecimento produzido socialmente pelo Jornalismo: “...o critério jornalístico de uma informação está indissoluvelmente ligado à reprodução de um evento pelo ângulo de sua singularidade. Mas o conteúdo da informação vai estar associado (contraditoriamente) à particularidade e universalidade que nele se propõem, ou melhor, que são delineados ou insinuados pela subjetividade do jornalista. O singular, então, é a forma do Jornalismo, a estrutura interna através da qual se cristaliza a significação trazida pelo particular e o universal que foram superados. O particular e o universal são negados em sua preponderân- cia ou autonomia e mantidos como o horizonte do conteúdo" ${ }^{34}$.

"Assim, como jornalista, você evidentemente tem a sensibilidade da existência" ${ }^{35}$, observa Freire a partir desta característica. A cristalização no singular explica também como o Jornalismo consegue produzir informação nova com uma grande economia de meios em relação aos outros modos de conhecimento. "Como o novo aparece sempre como singularidade, e esta sempre como o aspecto novo do fenômeno, a tensão para captar o singular abre sempre uma perspetiva crítica em relação ao processo. A singularidade tende a ser crítica porque ela é a realidade transbordando do conceito, a realidade se recriando e se diferenciando de si mesma" ${ }^{36}$.

\section{JORNALISMO:TEXTOE CONTEXTO}

Pode-se assim chegar mais perto do que seria uma fisiologia normal do Jornalismo como forma de produção e reprodução de conhecimento. É possível, como propõe Lage, isolar teoricamente "uma organização relativamente estável" 37 , dissociando esse "componente lógico" das ideologias que inevitavelmente o contaminam na realidade concreta - o "componente ideológico" que caracteriza a patologia diagnosticada pelos seus críticos, para encontrar a sua especificidade, uma vez que a ideologia é um fenômeno social mais geral. Esta perspectiva também encontra guarida na posição de Freire sobre a mídia. "Ao pensar sobre o problema

33. MEDITSCH, E. Método científico e método jornalístico. Revista Brasileira de Comunicação - Intercom. São Paulo: Intercom, n. 60, $1^{\circ}$ sem, 1989. p. 55-61.

34. GENRO FILHO, Adelmo, O segredo da pirâmide... op. cit. p. 163.

35. FREIRE, P. GUIMARĀES, S. Aprendendo... op. cit. p. 70.

36. GENRO FILHO, Adelmo. O segredo da pirâmide... op. cit. p. 212.

37. LAGE, N. Ideologia... op. cit. p. 37. 
dos chamados meios de comunicação, portanto, fica claro, logo assim de saída, que me sinto um homem do meu tempo. Não sou contra a televisão. Acho, porém, que é impossível pensar o problema dos meios sem pensar a questão do poder. $\mathrm{O}$ que vale dizer: os meios de comunicação não são bons nem ruins em si mesmos. Servindo-se de técnicas, eles são o resultado do avanço da tecnologia, são expressões da criatividade humana, da ciência desenvolvida pelo ser humano. $\mathrm{O}$ problema é perguntar a serviço de quê e a serviço de quem os meios de comunicação se acham. E esta é uma questão que tem a ver com o poder e que é política, portanto. A convicção que tenho, é a de que, resolvida essa situação, de fato problemática, do ponto de vista técnico você tem solução"38.

\begin{tabular}{c}
\hline É preciso ressaltar que o \\
conteúdo do Jornalismo, ao \\
estar preso ao senso comum, \\
está também necessariamente \\
vinculado a um contexto. O \\
texto só adquire sentido dentro \\
de um contexto.
\end{tabular}

Isto dificulta tanto a sistematização quanto a acumulação destes conteúdos, contrariamente ao que ocorre com a Ciência que isola o texto do contexto. Mas, neste sentido, o conhecimento produzido pelo Jornalismo é mais sintético e mais holístico do que aquele produzido pela Ciência. Neste aspecto, criticando a postura de uma certa Ciência Social tecnicista,
Freire também reconhecerá um mérito na atividade jornalística. "O descaso pelos sentimentos como deturpadores da pesquisa e de seus achados, o medo da intuição, a negação categórica da emoção e da paixão, a crença nos tecnicismos, tudo isso termina por nos levar a convencer-nos de que, quanto mais neutros formos em nossa ação, tanto mais objetivos e eficazes seremos. Mais exatos, mais cientistas, nada ideólogos nem jornalistas, portanto. Não quero negar a possibilidade de um especialista estranho ao contexto onde se deu ou onde se está dando uma certa prática fazer parte de uma equipe avaliadora com acerto e eficácia. Sua eficácia, porém, vai depender da capacidade que tenha de abrir-se à alma da cultura onde se deu ou se está dando a experiência e não apenas da capacidade, também necessária, de apreender a racionalidade da experiência por meio de caminhos múltiplos. Abrir-se à alma da cultura é deixar-se molhar, ensopar das águas culturais e históricas dos indivíduos envolvidos na experiência" ${ }^{39}$.

Embora nesta perspectiva se considere que o Jornalismo produz e reproduz conhecimento, não apenas de forma válida mas também útil para as sociedades e seus indivíduos, não se pode deixar de considerar que esse conhecimento, por ele produzido, tem os seus próprios limites lógi$\cos$ e, quando observado na prática, apresenta também uma série de problemas estruturais. Como toda outra forma de conhecimento, aquela que é produzida pelo Jornalismo será sempre condicionada histórica e culturalmente por seu contexto e subjetivamente por aqueles que 
participam desta produção. Estará também condicionada pela maneira particular como é produzida.

Nas últimas décadas se multiplicaram os trabalhos científicos que salientam o fato de o Jornalismo não ser uma imagem da realidade extraída unicamente desta realidade, mas sim uma construção onde os projetos, as técnicas e seu manejo, as ferramentas e as matérias-primas também interferem no produto final ${ }^{40}$. Inúmeras mediações condicionam o modo que o Jornalismo cria e processa a informação sobre a realidade, desde o schemata profissional ${ }^{41}$ - o modo particular como os jornalistas vêem o mundo, passando pelos objetivos, a estrutura e a rotina das organizações onde trabalham, as condições técnicas e econômicas para a realização de suas tarefas e, finalmente, o jogo de poder e os conflitos de interesses que estão inextricavelmente implicados na circulação social desta informação $0^{42}$.

\section{Um dos principais problemas} do Jornalismo como modo de conhecimento é a falta de transparência destes condicionantes.

A notícia é apresentada ao público como sendo a realidade e, mesmo que o público perceba que se trata apenas de uma versão da realidade, dificilmente terá acesso aos critérios de decisão que orien- taram a equipe de jornalistas para construí-la, e muito menos ao que foi relegado e omitido por estes critérios, profissionais ou não.

Neste ponto, a proliferação recente de instituições como o provedor de leitores - o ombudsman - e os observatórios de imprensa são certamente um progresso, não apenas pelo que possam discutir diretamente da produção da mídia, mas também por contribuir para levantar o véu que encobre os procedimentos habituais de construção da informação jornalística. Outro avanço, destacado por Freire, é a abertura da mídia ao diálogo com o público através das formas de interatividade disponibilizadas pela técnica, como na década de 80 já se observava no rádio ${ }^{43}$.

Também problemática para o Jornalismo enquanto conhecimento é a velocidade de sua produção. O Jornalismo se caracteriza pela dupla contemporaneidade: relato atual de fatos atuais, e cada vez mais pela instantaneidade, perseguindo a simultaneidade entre o relato e o relatado. No entanto, ao mesmo tempo que a velocidade representa um limite, representa também uma vantagem em relação a outros modos de conhecimento, já que a velocidade não é uma característica exclusiva do jornalismo, mas sim da civilização em que vivemos e que, por funcionar assim, necessita de informações produzidas rapidamente. "Hoje o poder, por exemplo, é de quem tem informações e as manipula para dirigir a comunicação" ${ }^{44}$, observa Freire, salientando a importância estraté-

40. TRAQUINA, N. (org.) Jornalismo: questōes, teorias e estórias. Lisboa: Veja, 1993.

41. MÉRO, L. Ways of thinking. The limits of rational thought and artificial intelligence. (Maneiras de pensar. Os limites do pensamento racional e inteligência artificial) Singapore: World Scientific, 1990.

42. MESQUITA. M. (org.) Comunicaşão e Política. Revista de Comunicação e Linguagens. 21/22 Lisboa: CECL UNL, 1996.

43. FREIRE, P. GUIMARĀES, S. Sobre... op. cit. p. 29.

44. FREIRE, P. Apud. PASSETTI, E. Conversação libertária com Paulo Freire. São Paulo: Imaginário, 1998. p. 103. 
gica da velocidade da informação e da comunicação para a luta política no novo contexto globalizado.

E, por fim, há que considerar a espetacularização como um aspecto problemático do jornalismo como conhecimento. $\mathrm{O}$ que distingue uma matéria jornalística de um relato científico, de um texto didático ou de um relatório policial é o fato de que se dirige a pessoas que não têm obrigação de ler aquilo. Em consequiência, procura, de alguma forma, aliciar as pessoas para que se interessem por aquela informação, através de técnicas narrativas e dramáticas. Para Freire, este tipo de preocupação também deveria estar presente na escola: “... sonhamos com uma escola que, sendo séria, jamais vire sisuda. A seriedade não precisa ser pesada. Quanto mais leve é a seriedade, mais eficaz e convincente é ela. Sonhamos com uma escola que, porque séria, se dedique ao ensino de forma competente, mas, dedicada, séria e competente ao ensino, seja uma escola geradora de alegria"45.

No Jornalismo, o uso de técnicas narrativas e de espetacularização se justifica amplamente pela eficácia comunicativa e cognitiva que proporcionam. O problema é quando passam a ser utilizadas em função de objetivos que não os cognitivos, como a luta comercial por audiência e o esforço político de persuasão. No cotidiano do Jornalismo praticado em nossas sociedades, é muito difícil distinguir entre estes três tipos de objetivo.

Da mesma forma, é difícil discernir sobre as origens e os objetivos que orientaram o desenvolvimento de determina- dos formatos e técnicas editoriais, consagrados hoje por sua eficácia no contexto da mídia comercial. Em seus últimos escritos, Freire deixou uma crítica à linguagem da televisão (leia-se: do telejornalismo) que, segundo ele, utiliza "uma sintaxe que reduz a um mesmo plano o passado e o presente e sugere que o que ainda não há já está feito. Mais ainda, que diversifica temáticas no noticiário sem que haja tempo para a reflexão sobre os variados assuntos. De uma notícia sobre Miss Brasil se passa a um terremoto na China; de um escândalo envolvendo mais um banco dilapidado por diretores inescrupulosos temos cenas de um trem que descarrilou em Zurique. O mundo encurta, o tempo se dilui. $\mathrm{O}$ ontem vira agora; o amanhã já está feito. Tudo muito rápido. Debater o que se diz e o que se mostra e como se mostra na televisão me parece algo cada vez mais importante" 46 .

\section{APERFEIÇOAMENTO DO JORNALISMO}

Embora tão crítica em relação à mídia e ao Jornalismo quanto sempre foi em relação à educação, a visão de Freire também aí não se contenta apenas com a crítica. "A alfabetização em televisão não é lutar contra a televisão, uma luta sem sentido..." ${ }^{47}$. Pelo contrário, aponta para a busca de alternativas na prática. "É certo que mulheres e homens podem mudar o mundo para melhor, para fazê-lo menos injusto, mas a partir da realidade concreta a que 'chegam' em sua geração. E não fundadas ou fundados em devaneios, fal- 
sos sonhos sem raízes, puras ilusões. $\mathrm{O}$ que não é porém possível é sequer pensar em transformar o mundo sem sonho, sem utopia e sem projeto. (...) A transformação do mundo necessita tanto do sonho quanto a indispensável autenticidade deste depende da lealdade de quem sonha às condições históricas, materiais, aos níveis de desenvolvimento tecnológico, científico do contexto do sonhador. Os sonhos são projetos pelos quais se luta. (...) Possivelmente, um dos saberes fundamentais mais requeridos para o exercício de um tal testemunho é o que se expressa na certeza de que mudar é difícil mas é possível. É o que nos faz recusar qualquer posição fatalista que empresta a este ou àquele fator condicionante um poder determinante, diante do qual nada se pode fazer"48.

A perspectiva da prática é o que torna o desenvolvimento de um método Paulo Freire de jornalismo um profícuo campo de investigação acadêmica e profissional. Um método pensado não para o desenvol-

Resumo: A aplicação da filosofia práxica do pedagogo Paulo Freire pode possibilitar um avanço na compreensão dos condicionamentos das práticas cognitivas inerentes à atividade jornalistica, tanto no pólo da produção quanto no da recepção, assim como contribuir para o aperfeiçoamento destas práticas sociais no ambiente democrático. A partir de uma releitura da obra do pedagogo, confrontada com a concepção do jornalismo como conhecimento, este trabaIho aponta para a oportunidade do desenvolvimento e aplicação de um "método Paulo Freire" no fazer jornalístico.

Palavras-chave: jornalismo, conhecimento, Paulo Freire, teoria, método, ciência vimento de um jornalismo ideal para uma sociedade ideal, mas para o aperfeiçoamento da prática real em condições limitadas, para a intervenção na realidade contraditória, enfrentando "situações-limite para a concretização de um inédito viável" ${ }^{\prime 4}$.

O desenvolvimento de tal método certamente se apoiaria na filosofia de Freire sobre a educação, em sua teoria do conhecimento e em sua experiência pedagógica, confrontando os conceitos e as técnicas às necessidades da prática jornalística e às suas particularidades. Requer, portanto, não apenas conhecimento da obra de Freire, mas também domínio da atividade profissional.

Tal método se aplicaria tanto à produção do Jornalismo, enquanto prática cognitiva dos jornalistas, quanto à sua recepção pelo público, a partir da qual a atividade cognitiva se refaz. E, certamente, teria conseqüências importantes também no ensino do Jornalismo.

(The Paulo Freire Philosophy and cognitive practices in journalism)

Abstract: Applying Paulo Freire's praxic philosophy may allow for advances in the understanding of the conditioning of cognitive practices inherent to the journalistic activity, both in the production and in the reception poles, and it may also contribute to perfecting these social practices in the democratic environment. Based on a new reading of Freire's work, confronted with the conception of journalism as knowledge, this work points to the opportunity of developing and applying a "Paulo Freire method" to journalistic production.

Key words: journalism, knowledge, Paulo Freire, theory, method, science

48. FREIRE, P. Pedagogia da indignação. op. cit. p. 55.

49. FREIRE, P. Pedagogia do oprimido. Rio de Janeiro: Paz e Terra, 1970. p. 110. 